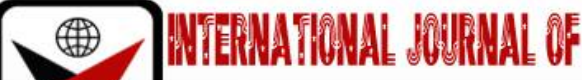

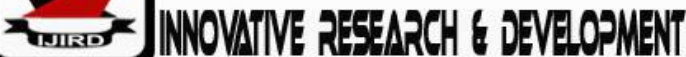

ISSN 2278 - 0211 (Online)

\section{Chemical Composition, Antimicrobial and Antioxidant Activities of Root Essential Oil of Nigerian Specie of Asparagus Flagellaris (Kunth) Baker}

\begin{tabular}{|c|} 
Oluwakayode O. Odeja \\
Lecturer, Department of Chemistry, \\
Federal University of Petroleum Resources, Effurun, Delta State, Nigeria \\
Michael G. Ibok \\
Ph.D. Student, Department of Chemistry, University of Ibadan, Nigeria \\
Ejike O. Okpala \\
Assistant Lecturer, Department of Chemistry, Federal University Lokoja, Kogi, Nigeria \\
Ufoma Akpaeva \\
B.Sc Student, Department of Chemistry, \\
Federal University of Petroleum Resources, Effurun, Delta State, Nigeria
\end{tabular}

\begin{abstract}
:
Asparagus flagellaris (Asparagaceae) root have a variety of medicinal uses including treatment of syphilis, gonorrhea and other sexually transmitted diseases, with no report on its essential oil composition. This study investigated the quantitative and qualitative characterising of the chemical composition, evaluating the antimicrobial and antioxidant activities of root essential oil from A. flagellaris. The essential oil was obtained by hydrodistillation method using Clevenger apparatus, the identification and characterisation were done by gas chromatography-mass spectrometry (GC-MS) technique. Antimicrobial properties were assessed by broth dilution method and the antioxidant activity were evaluated by 2,2'-diphenyl-1-picrylhydrazyl (DPPH•) method. A pale-yellow essential oil with characteristic aroma was obtained with a yield of $0.44 \%$ (w/w). GC/MS analysis revealed the presence of nineteen (19) compounds representing $97.03 \%$ of the total oil composition. The essential oil was predominated by $84.54 \%$ thymol derivatives. The root essential oil showed moderate inhibitory zone (18 - $10 \mathrm{~mm})$ when compared with the reference standards Gentamicin and Tioconazole for both bacteria (40 - $35 \mathrm{~mm}$ ) and fungi (28 mm) respectively. The root essential oil can be classified as bacteriostatic on test organisms. The oil exhibited a distinct antioxidant activity due the synergy of the identified constituents and IC $C_{50}$ values of scavenging abilities on DPPH radicals were Ascorbic acid $(0.1734 \mathrm{mg} / \mathrm{mL})>$ BHA $(0.1954 \mathrm{mg} / \mathrm{mL})>$ essential oil $(0.3162 \mathrm{mg} / \mathrm{mL})$. The root essential oil of A. flagellaris contains important chemical compounds that are liable for its antioxidant and antimicrobial activities.
\end{abstract}

Keywords: Asparagus flagellaris, root essential oil, antioxidant activity, gc/ms analysis, antimicrobial activity, thymol derivatives

\section{Introduction}

Asparagus flagellaris (Kunth) Baker is widespread in tropical Africa with characteristics offensive scent. A. flagellaris belongs to the family Asparagaceae. It grows to a dimension of about $1 \mathrm{~m}$ and is scandent or more/less erect plant with arching spiny branchlets produced from a woody rootstock (Burkill, 1985). The plant is widely used as a food and medicine in Africa. The branchlets (cladodes) are the main adjunct of herbal medicine to treat guinea worm and as a gel for hair growth (Vander Burg, 2004). The root has a variety of medicinal uses; they are added to food or baths for treating syphilis, gonorrhea and other transmitted diseases - either being macerated or decocted. The hot brew is used to cure diarrhea and urinary infections (Burkill, 1985, Vander Burg, 2004). The phytochemical screening of the stem bark and leaves of A. flagellaris showed the appreciable amount of flavonoid and moderate amount of carbohydrate, cardiac glycoside and saponin while reducing sugar, ketones and pentose were detected in trace amount (Mshelia et al., 2008). Mshelia and coworkers also reported the inhibition of six organisms viz Escherichia coli, Corynebacteria, Klebsiella, Neiserra gonorrhoeae, Shegiella dysentariae and Candida albicans, at various concentrations of the ethanol extract, while the aqueous extract was susceptible to five organisms namely Corynebacteria, Streptococcus pyogene, Proteus specie, Neiserra gonorrhoeae, and Treponema palladium (Mshelia et al., 2008).

The study of aromatic and medicinal plants enable finding producing effective essential oils that have a considerate level of application both in food and medicine. A good number of them are biologically active against a wide range of organisms such as bacteria, fungi, viruses and protozoa. In recent time, a good number of essential oils and their components have been invested for their antioxidant and antimicrobial properties against bacteria and fungi (Kalemba and Kunicka, 2003). Hence, this paper focuses on the chemical compositions, anti-oxidant and anti-microbial activities of the root essential oil from A. flagellaris. 


\section{Materials and Methods}

\subsection{Plant Materials}

A. flagellaris root was collected in June 2019 at Efurum, Delta State, Nigeria. Identification and authentication were carried out at the Herbarium Unit, Department of Botany, University of Ibadan, Nigeria.

\subsection{Isolation of Essential Oils}

The oil was obtained from the chopped fresh root (467.44 g) of A. flagellaris by hydro-distillation on a Clevenger type apparatus for 4 hours following the British pharmacopeia specifications (British Pharmacopoeia, 1981). $2 \mathrm{~mL}$ of hexane was intermittently added to aid the trapping of the oil during the process. The essential oil was stored at $4{ }^{\circ} \mathrm{C}$ erstwhile analysis.

The \% yield of the oil was calculated using:

$$
\% \text { Yield }=\frac{\text { Weight of Essential Oil }}{\text { Weight of Sample }} \times 100
$$

\subsection{Identification and Quantification of the Essential Oil Constituents}

The root of A. flagellaris essential oil subjected to GC-MS analysis on an Agilent 7809A Gas Chromatography hyphenated with an Agilent Mass Detector having split/splitless injector interfaced to mass selective detector operating at $70 \mathrm{eV}$. The ion source temperature was set to $200 \mathrm{oC}$ above a mass spectral range of $50-700(\mathrm{~m} / \mathrm{z})$ at a scan rate of 1428 $\mathrm{amu} / \mathrm{sec}$. The column of the GC used was HP-5MS with a length of $30 \mathrm{~m}$, with an internal diameter of $0.25 \mathrm{~mm}$ and a film thickness of $0.25 \mu \mathrm{m}$. The oven temperature was automated as follows: initial temperature $80 \mathrm{oC}$ for $2 \mathrm{~min}$, increased at $10 \mathrm{oC} / \mathrm{min}$ to a temperature of $240 \mathrm{oC}$ for 6 minutes. The carrier gas (Helium) was used at a flow rate of $1 \mathrm{~mL} / \mathrm{min}$. Injection volume; linear velocity and pressure were adjusted at $1.0 \mu \mathrm{L}, 362 \mathrm{~cm} / \mathrm{s}$ and $56.2 \mathrm{KPa}$ respectively. The oven temperature was set at $60 \mathrm{oC}$, hold for $1 \mathrm{~min}$ to $180 \mathrm{oC}$ for $3 \mathrm{~min}$ at $10 \mathrm{oC} / \mathrm{min}$, the final temperature was $280 \mathrm{oC}$ for $2 \mathrm{~min}$ at $10 \mathrm{oC} / \mathrm{min}$ both the injector and detector temperatures were fixed at $250 \mathrm{oC}$. Identification of the essential oil components was based on comparison of their mass spectral fragmentation patterns (NIST database 14.L/Chemstation data system) with the data previously reported in the literature (Adams, 2001).

\subsection{Anti-Microbial Activity on A. Flagellaris Root Essential Oil}

Root essential oil of A. flagellaris was tested against 10 strains of micro-organisms consisting 6 bacteria; 3 Gram negative (Escherichia coli, Pseudomonas aeruginosa, Klebsiella pneumonia), 3 Gram-positive (Staphylococcus aureus, Salmonella typhimurium and Bacillus substilis) and 4 fungi (Candida albicans, Penicillum notatum, Aspergillus niger and Rhizopus spp.). All microbes were clinical isolates obtained from the Department of Pharmaceutical Microbiology, University of Ibadan, Oyo State, Nigeria. Broth dilution and surface plate methods were employed for antibacterial and antifungal activities, respectively (Mshelia et al., 2008, Bauer and Kirby, 1966.). Five (5) concentrations of the essential oil were prepared, 62.50, 125, 250, 500 and $1000 \mu \mathrm{g} / \mathrm{mL}$ and $1 \mathrm{~mL}$ aliquot of each concentration of the essential oil was tested for bioactivity. DMSO was used as a negative control, Gentamicin as a positive control for bacteria and Tioconazole as positive control for Fungi. All test and analysis were carried out in duplicates. Observed zones of inhibition of growth were measured and recorded in millimeter $(\mathrm{mm})$.

\subsection{Antioxidant Activity on A. flagellaris Root Essential Oil}

Free radical scavenging activity on 2,2'-diphenyl-1-picrylhydrazyl radical (DPPH) was carried out using the method described by Brand-William et al. (1995) to evaluate the antioxidant activity of root essential oil of A. flagellaris. A solution of $100 \mathrm{mM}$ (DPPH) in methanol was prepared. Five (5) concentration $(1.0,0.5,0.25,0.125 \mathrm{and} 0.0625) \mathrm{mg} / \mathrm{mL}$ was prepared to determine free radical scavenging activity of the oil at by measuring the decrease in absorption after 30 minutes of incubation at $517 \mathrm{~nm}$ in a UV/visible spectrophotometer. A decrease in absorption was measured against that of the control. The same experiment was repeated on ascorbic acid and butylated hydroxyanisole (BHA), well known antioxidant agents. All test and analysis were carried out in triplicates. The activities were also determined as a function of their \% Inhibition which was calculated using the formula:

$$
\% \mathrm{I}=\frac{(\mathrm{Ab}-\mathrm{As})}{(\mathrm{Ab})} \times 100
$$

Where Ab: Absorbance of blank. As: Absorbance of Sample. \%I: Percentage of Inhibition.

\subsection{Statistical Analysis}

All results were conveyed as means \pm standard deviation. $50 \%$ inhibition concentration (IC50) of the samples and Pearson $r$ was used to determine any significant difference $(\mathrm{p}<0.05)$ between groups using the statistical analysis software package GraphPad 5.0. All graph/chart was drawn with GraphPad 5.0.

\section{Results and Discussions}

\subsection{Essential Oils Isolation}

$467.44 \mathrm{~g}$ of freshly chopped root A. flagellaris sample gave $2.08 \mathrm{~g}$ essential oil via hydro-distillation with light yellow colour and characteristics aroma. The percentage yield (w/w) obtained was $0.44 \%$. The yield is an indication that A. flagellaris is rich in essential oil content. 


\subsection{Chemical Composition of the Root A. Flagellaris Essential Oil}

The qualitative and quantitative data on the volatile metabolites of the essential oil from the root of A. flagellaris are summarised in Table 1. The preliminary GC analyses showed the presence of nineteen (19) compounds (representing $97.03 \%$ of the oil) were identified. The identification of the individual GC peaks was by comparison of their relative retention time $(\mathrm{tB})$ with those of authentic samples on the HP-5MS packed column and the computer searching followed by matching the mass spectral (MS) data with those held in the NIST database 14.L/Chemstation data system. The essential oil was predominantly in nature (84.54\%) thymol derivatives (thymol methyl ether, thymol hydroquinone dimethylether, thymol isobutyrate, 8, 9-dehydro-4-hydroxy thymol dimethylether, thymyl-2-methylbutyrate and thymyl tiglate). $3.64 \%$ oxygenated monoterpenes (Durenol and 1-(2, 5-dimethoxyphenyl)-Ethanone), $3.10 \%$ hydrogen sesquiterpenes (Cis- $\beta$-Farnesene, $\alpha$-Santalene, $\alpha$-Humulene, $\beta$-Bisabolene and $\delta$-Cadinene), $1.36 \%$ oxygenated sesquiterpenes ( $\alpha$-Bisabolol) and 10.99\% non-terpenes/non-terpenoids. Willuhn (1972) reported 5 thymol derivatives as the major constituents of the oil of underground organs of A. montana, i.e. 4-hydroxythymol dimethyl ether (46\%), 4hydroxy-8, 9-didehydrothymol dimethyl ether (18\%), thymol methyl ether (12\%), 8, 9-didehydrothymol methyl ether $(3 \%)$ and thymol isobutyrate (8\%). A similar trend was observed by Weremczuk-Jeżyna et al. (2011) in hairy roots and plant roots of Arnica montana L. essential oils that contained mainly of bi-functional thymol derivatives and sesquiterpene hydrocarbons. The most abundance constituents observed in the root essential oil of A. flagellaris are as follows thymyl tiglate $-34.73 \%$, thymol methyl ether - $25.80 \%$, thymol hydroquinone dimethylether $-12.72 \%$, thymyl-2-methylbutyrate 5.47\%, Durenol - 3.29. The structures of six (6) major thymol derivatives identified in this study are presented in Fig. 1.

Possibly, most of the reputed medicinal properties of A. flagellaris in folk medicine are due to the presence of relatively high amount of thymol derivative in the essential oil. The strong antiseptic, anti-inflammatory, antibacterial, antifungal and flavor properties as well as antispasmodic activities of thymol derivatives are well documented in the literature (Sticher, 1977). The occurrence of other minor constituents of the essential oil is of phytochemical interests due to their synergetic action in the inhibition of the biological activities observed in this studied.

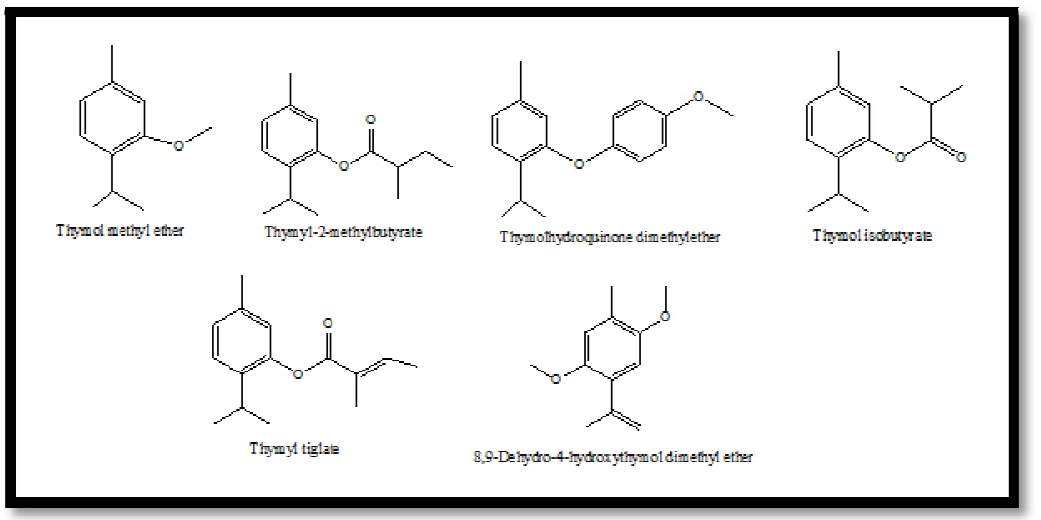

Figure 1: Structures of Thymol Derivatives from Root Essential Oil of A. Flagellaris

\begin{tabular}{|c|c|c|}
\hline $\mathbf{S} / \mathbf{N}$ & Compounds Identified & \% Composition \\
\hline 1 & Durenol & 3.29 \\
\hline 2 & Thymyl-2-methylbutyrate & 5.47 \\
\hline 3 & $\alpha$-Santalene & 0.8 \\
\hline 4 & n-octylesterundecanoic acid & 0.98 \\
\hline 5 & Isophosphinoline & 0.76 \\
\hline 6 & Thymol methyl ether & 25.8 \\
\hline 7 & 2'-Hydroxy-1'-acetonaphthone & 1.77 \\
\hline 8 & Euparin & 0.64 \\
\hline 9 & Thymolhydroquinone dimethylether & 12.72 \\
\hline 10 & 2-isopropenyl-(+)-2-carene & 0.24 \\
\hline 11 & Cis- $\beta$-Farnesene & 0.26 \\
\hline 12 & 8,9-dehydro-4-hydroxy thymol dimethylether & 1.49 \\
\hline 13 & $\alpha$-Humulene & 0.37 \\
\hline 14 & Thymolisobutyrate & 4.33 \\
\hline 15 & $\beta$-Bisabolene & 0.88 \\
\hline 16 & $\delta$-Cadinene & 0.79 \\
\hline 17 & 1-(2,5-dimethoxyphenyl)-Ethanone & 0.35 \\
\hline 18 & Thymyl tiglate & 34.73 \\
\hline \multirow[t]{2}{*}{19} & $\alpha$-Bisabolol & 1.36 \\
\hline & Total & 97.03 \\
\hline
\end{tabular}

Table 1: Chemical Composition of the Root Essential Oil of A. Flagellaris 


\subsection{Antimicrobial Activity of Root Essential Oil of A. flagellaris}

Experimental data obtained from the antimicrobial activity are reported in Table 2. The effect of the root essential oil of A. flagellaris was compared with reference positive control, for the same volumes against selected bacteria and fungi (see Fig. 2 and 3).

The in-vitro antimicrobial activity of the root A. flagellaris essential oil against the microorganisms employed and its activity potentials were qualitatively and quantitatively assessed by the presence or absence of inhibition zones and zone diameters values in comparison with the standard antimicrobial drugs Gentamicin and Tioconazole. The result revealed that the root essential oil showed moderate inhibitory zone $(18-10 \mathrm{~mm})$ when compared with the reference standards for both bacteria $(40-35 \mathrm{~mm})$ and fungi $(28 \mathrm{~mm})$. No effect was detected against Pseudomonas aeruginosa and Salmonella typhi at all tested concentrations. It can be said the essential oil is more active against gram-positive aerobic organisms at all tested concentration for this study. Escherichia coli $(16-12 \mathrm{~mm})$ and Klebsiella pneumonia $(14-10 \mathrm{~mm})$ showed inhibition at higher concentration $(1000-250 \mu \mathrm{g} / \mathrm{mL})$, but no effect was observed at lower concentration as shown in Table 2. A similar trend was observed for the fungi (Penicillum notatum and Rhizopus spp.), showing inhibition at higher concentration $(1000-250 \mu \mathrm{g} / \mathrm{mL})$, but no effect at lower concentrations $(125-62.5 \mu \mathrm{g} / \mathrm{mL})$. The root essential oil was susceptible on the following tested organisms, Escherichia coli, Klebsiella pneumonia, Staphylococcus aureus, Bacillus subtilis, Candida albicans, Penicillum notatum, Aspergillus niger and Rhizopus spp.

Hence, the moderate activity of the essential oil could be attributed to the synergetic action of the volatile metabolites identified. Although, the absence of antimicrobial active compounds such as linalool, linalyl acetate, $\alpha$-pinene, terpineol and camphor, credited with potent antimicrobial and antifungal effects (Dorman and Deans, 2000, Magiatis et al., 2002, Soković et al., 2010). The activity of this essential oil can be described as 'bacteriostatic antibiotic' - is assumed to require phagocytic cells to clear bacteria and are therefore thought to be less effective without an efficient immune response. This result correlates with the earlier report by Marchese et al. (2016) that described all the thyme essential oils as bacteriostatic against the microorganisms.

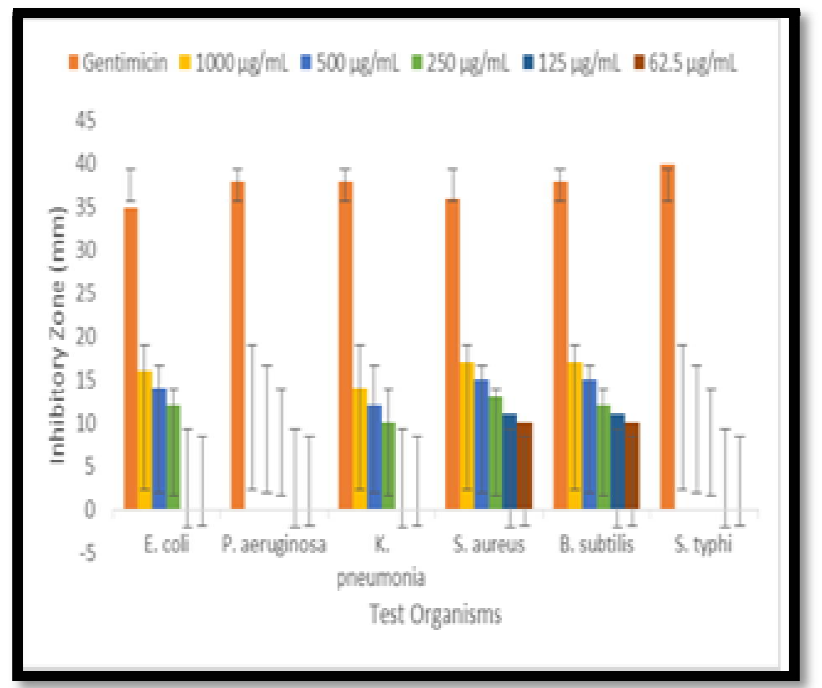

Figure 2: Antibacterial Inhibitory Zone of the Root Essential Oil A. Flagellaris against Test Organisms with Standard

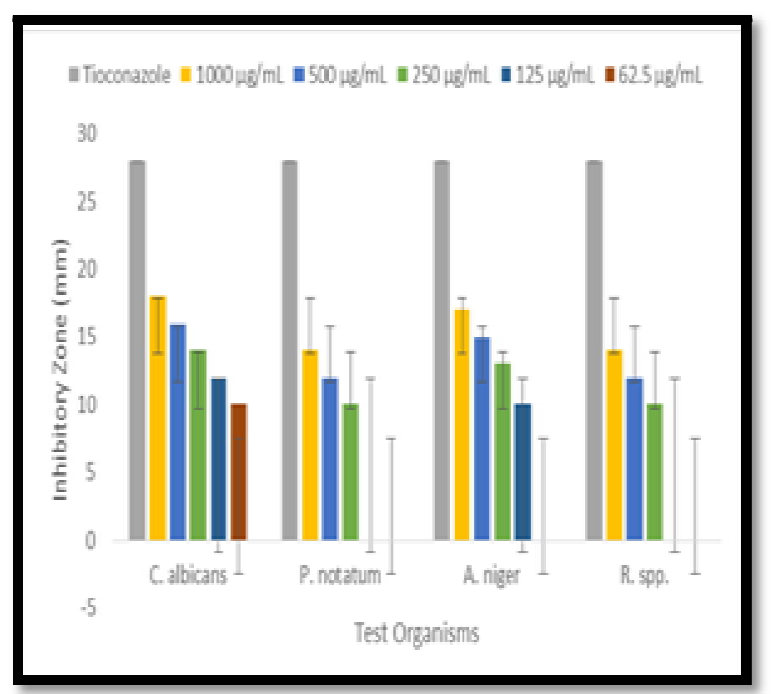

Figure 3: Antifungal Inhibitory Zone of the Root Essential of A. Flagellaris against Test Organisms with Standard 
The result correlated to the antibacterial activity of the crude extracts of A. flagellaris stem, bark and leaf, that reported ethanol extract inhibition on the growth of six organisms viz Escherichia coli, Corynebacteria, Klebsiella, Neiserra gonorrhea, Shegiella dysentariae and Candida albicans, at various concentrations, while the aqueous extract were susceptible on five organisms namely Corynebacteria, Streptococcus pyogene, Proteus spp., Neiserra gonorrhea, and Treponema palladium (Mshelia et al., 2008).

\begin{tabular}{|c|c|c|c|c|c|c|c|c|}
\hline \multirow[t]{2}{*}{ Test Organisms } & \multirow{2}{*}{$\begin{array}{l}\text { Negative } \\
\text { Control }\end{array}$} & \multicolumn{2}{|c|}{ Positive Control } & \multicolumn{5}{|c|}{ Concentration $(\mu \mathrm{g} / \mathrm{mL})$} \\
\hline & & Gentamicin & Tioconazole & 1000 & 500 & 250 & 125 & 62.5 \\
\hline Escherichia coli & $(-)$ & 35 & $\mathrm{~N} / \mathrm{A}$ & $16 \pm 0.00$ & $14 \pm 0.00$ & $12 \pm 0.00$ & $(-)$ & $(-)$ \\
\hline $\begin{array}{c}\text { Pseudomonas } \\
\text { aeruginosa }\end{array}$ & $(-)$ & 38 & $\mathrm{~N} / \mathrm{A}$ & $(-)$ & $(-)$ & $(-)$ & $(-)$ & $(-)$ \\
\hline Klebsiella pneumonia & $(-)$ & 38 & $\mathrm{~N} / \mathrm{A}$ & $14 \pm 0.00$ & $12 \pm 0.00$ & $10 \pm 0.00$ & $(-)$ & $(-)$ \\
\hline $\begin{array}{c}\text { Staphylococcus } \\
\text { aureus }\end{array}$ & $(-)$ & 36 & $\mathrm{~N} / \mathrm{A}$ & $17 \pm 1.41$ & $15 \pm 1.41$ & $13 \pm 1.41$ & $11 \pm 1.41$ & $10 \pm 0.00$ \\
\hline Bacillus subtilis & $(-)$ & 38 & $\mathrm{~N} / \mathrm{A}$ & $17 \pm 0.00$ & $15 \pm 0.00$ & $12 \pm 0.00$ & $11 \pm 0.00$ & $10 \pm 0.00$ \\
\hline Salmonella typhi & $(-)$ & 40 & $\mathrm{~N} / \mathrm{A}$ & $(-)$ & $(-)$ & $(-)$ & $(-)$ & $(-)$ \\
\hline Candida albicans & $(-)$ & $\mathrm{N} / \mathrm{A}$ & 28 & $18 \pm 0.00$ & $16 \pm 0.00$ & $14 \pm 0.00$ & $12 \pm 0.00$ & $10 \pm 0.00$ \\
\hline Penicillum notatum & $(-)$ & $\mathrm{N} / \mathrm{A}$ & 28 & $14 \pm 0.00$ & $12 \pm 0.00$ & $10 \pm 0.00$ & $(-)$ & $(-)$ \\
\hline Aspergillus niger & $(-)$ & $\mathrm{N} / \mathrm{A}$ & 28 & $17 \pm 1.41$ & $15 \pm 1.41$ & $13 \pm 1.41$ & $10 \pm 1.41$ & $(-)$ \\
\hline Rhizopus spp. & $(-)$ & $\mathrm{N} / \mathrm{A}$ & 28 & $14 \pm 0.00$ & $12 \pm 0.00$ & $10 \pm 0.00$ & $(-)$ & $(-)$ \\
\hline
\end{tabular}

Table 2: Antimicrobial Activity of Root Essential Oil of A. Flagellaris

Inhibitions Are Expressed In Mm. (-): No Activity. N/A: Not Applicable, $\pm=$ Standard Deviation

\subsection{Antioxidant Activity of the Root Essential Oil of A. Flagellaris}

The percentage inhibition and $\mathrm{IC}_{50}$ of root $A$. flagellaris essential oil compared with reference standard are shown in Table 3, while \% Inhibition of root essential oil at different concentration compared with standards was presented in Fig. 4. According to Ruberto and Baratta (2000) reported that phenolic compounds are effective antioxidants; thus, thymol derivatives, oxygenated monoterpenes and oxygenated sesquiterpenes molecules are indeed responsible for the antioxidant activity of this essential oil. The significant antioxidant activity observed in this study in the DPPH reduction can be explained by the ability of the identified compounds to donate a hydrogen atom. Since ascorbic acid is considered as polar compounds, the result of antioxidant activity of the essential oil was not only compared to it, so that the activity observed would not be considered as weak antioxidants, butylated hydroxyanisole (BHA) was used as the second reference standard. The potency of antioxidant activity and scavenging ability of the essential oil are inversely correlated with their $\mathrm{IC}_{50}$ values, i.e. the activities of the essential oil were as follows: Ascorbic acid $(0.1734 \mathrm{mg} / \mathrm{mL})>\mathrm{BHA}(0.1954$ $\mathrm{mg} / \mathrm{mL})>\operatorname{RTAF}(0.3162 \mathrm{mg} / \mathrm{mL})$.

\begin{tabular}{|c|c|c|c|c|c|c|}
\hline \multirow{2}{*}{$\begin{array}{c}\text { Test } \\
\text { samples }\end{array}$} & \multicolumn{5}{|c|}{ \% Inhibition at each Concentration (mg/mL) } & \multirow[b]{2}{*}{$\mathrm{IC}_{50}$} \\
\hline & 1 & 0.5 & 0.25 & 0.125 & 0.0625 & \\
\hline RTAF & $90.04 \pm 0.0000$ & $85.01 \pm 0.0000$ & $73.95 \pm 0.00$ & $61.43 \pm 0.0000$ & $50.73 \pm 0.0006$ & 0.3162 \\
\hline A. acid & $93.05 \pm 0.0006$ & $92.87 \pm 0.0006$ & $92.78 \pm 0.0012$ & $90.49 \pm 0.0001$ & $90.40 \pm 0.0000$ & 0.1734 \\
\hline BHA & $92.60 \pm 0.0006$ & $91.96 \pm 0.0000$ & $91.41 \pm 0.0000$ & $91.32 \pm 0.0000$ & $90.68 \pm 0.0012$ & 0.1954 \\
\hline
\end{tabular}

Table 3: Antioxidant Activity of the Root Essential Oil of A. Flagellaris

RTAF: Root Essential Oil of A. Flagellaris. A. Acid: Ascorbic Acid Butylated Hydroxyanisole. $\pm=$ Standard Deviation

It was observed that the essential oil in the study is concentration dependence, showing a competitive activity with ascorbic acid and BHA at a higher concentration as shown in Fig. 4. Statistical analysis (Pearson r) of the data showed that there was significantly different $(\mathrm{p}<0.005)$ between the essential oil and Ascorbic acid/BHA at $0.5-0.0625 \mathrm{mg} / \mathrm{mL}$, but there was no different between Ascorbic acid, BHA and the essential oil at $1 \mathrm{mg} / \mathrm{mL}$.

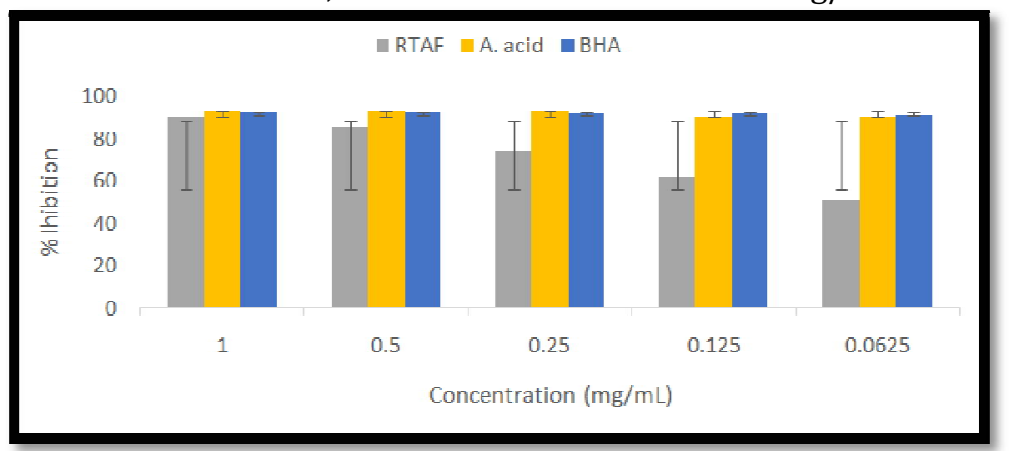

Figure 4: \% Inhibition of Root Essential Oil of A. Flagellaris Antioxidant Activity Compared with the Reference Standard 


\section{Conclusion}

This study revealed the potency of root essential oil of A. flagellaris as antioxidant agent with $\mathrm{IC}_{50}$ value of 0.3162 $\mathrm{mg} / \mathrm{mL}$. The essential oil was predominated by thymol derivative (84.54\%), $3.64 \%$ oxygenated monoterpenes, $3.10 \%$ hydrogen sesquiterpenes, $1.36 \%$ oxygenated sesquiterpenes and $10.99 \%$ non-terpenes/non-terpenoids. The oil with characteristics odour recorded susceptibility against some bacteria and fungi strains - Escherichia coli, Klebsiella pneumonia, Staphylococcus aureus, Bacillus subtilis, Candida albicans, Penicillum notatum, Aspergillus niger and Rhizopus spp respectively. Hence the biological activities of this study can be attributed to the synergy of the chemical constituents.

\section{Acknowledgements}

The authors are grateful to Departments of Chemistry and Pharmaceutical Microbiology, University of Ibadan, Nigeria for providing the laboratory space and facilities for the extraction and analysis of the essential oils.

\section{References}

i. Adams, R. (2001). Identification of essential oil components by gas chromatography/mass spectrometry. Carol Stream, IL.: Allured publishing corporation.

ii. Bauer, A. K. (1966.). Antibiotic susceptibility testing by standard disc method. Amer. J. Clin. Pathol.,, 10: 493-496.

iii. Brand-Williams, W. C. (1995). Use of a free-radical method to evaluate antioxidant activity. Food Science and Technology, 28:25-30.

iv. British Pharmacopoeia, I. (1981). London: HM Station.

v. Burkill, H. (1985). The Useful Plants of West Tropical Africa. London, United Kingdom.

vi. Dorman, H. D. (2000). Antimicrobial agents from plants: Antibacterial activity of plant volatile oils . J. Appl. Microbiol., 88: 308-816.

vii. Kalemba, D. K. (2003). Antibacterial and antifungal properties of essential oils. Curr. Med. Chem., 10: 813-829.

viii. Magiatis, P. S. (2002). Chemical Composition and in-vitro Antimicrobial Activity of the Essential Oils of Three Greek Achillea Species. Z. Naturforsch. C, 57: 287 - 290.

ix. Marchese, A. 0. (2016). Antibacterial and antifungal activities of thymol: a brief review of the literature. Food Chemistry, doi: http://dx.doi.org/10.1016.

x. Mshelia, E. Z. (2008). Phytochemical Analysis and Antibacterial Screening of Asparagus Flagellaris (Kunth) Bak, used in the Traditional Treatment of Sexually Transmitted Diseases and Urinary Infections. Ethiopian Journal of Environmental Studies and Management, 1(2): 44-48.

xi. Ruberto, G., \& Baratta, M. (2000). Antioxidant activity of selected essential oil components in two lipid model systems. Food Chem, 69:167-174.

xii. Soković, M. G. (2010). Antibacterial effects of the essential oils of commonly consumed medicinal herbs using an in vitro model. Molecules, 15: 7532-7546.

xiii. Sticher, 0. (1977). New Natural Products and Plant Drugs with Pharmacological, Biological or Therapeuticcal Activity. Berlin: (Wag ner, H., Wolff, P. eds.). Springer-Verlag.

xiv. Vander Burg, W. (2004). Asparagus fagellaris (Kunth) Baker. In G. a. Grubben, PROTA 2; Vegetables/legumes. Wageningen. Netherlands.

xv. Weremczuk-Jeżyna, I. W. (2011). Constituents of the Essential Oil from Hairy Roots and Plant Roots of Arnica montana L. . Journal of Essential Oil Research, 23(1): 91-9.

xvi. Willuhn, G. (1972). Investigation on the Constituents of Arnica Species VII. The Composition of the Essential Oil from the Underground Organs and Flower Baskets of Various Arnica Species. Planta Med., 22: 1-31. 